\title{
Defining technology user needs of Indigenous older adults requiring dementia care
}

\author{
Danette Starblanket $\mathrm{PhD}^{\mathrm{a}, *}$ \\ Megan E. O'Connell $\mathrm{PhD}^{\mathrm{b}}$ \\ Benjamin Gould BA ${ }^{b}$ \\ Mackenzie Jardine $\mathrm{BHS}^{\mathrm{c}}$ \\ Myles Ferguson $\mathrm{PhD}^{\mathrm{b}}$ \\ Carrie Bourassa $\mathrm{PhD}^{\mathrm{d}}$
}

\begin{abstract}
aJohnson Shoyama Graduate School of Public Policy, University of Saskatchewan, Saskatoon, Canada; ${ }^{b}$ Department of Psychology, University of Saskatchewan, Saskatoon, Canada; ' University of Regina, Regina, Canada; ${ }^{\mathrm{d} D e p a r t m e n t}$ of Community Health \& Epidemiology, College of Medicine, University of Saskatchewan, Canada; *Corresponding author: danette.starblanket@ usask.ca
\end{abstract}

\begin{abstract}
D. Starblanket, M.E. O'Connell, B. Gould, M. Jardine, M. Ferguson, C. Bourassa. Defining technology user needs of Indigenous older adults requiring dementia care. Gerontechnology 2019;18(3):142-155; https://doi.org/10.4017/gt.2019.18.3.002.00 Exploration of user needs for technology is critical for adoption and sustained use. We qualitatively examined needs for technology to enhance the wellbeing and support independent living of North American Indigenous older adults requiring dementia care. We partnered with Indigenous older adults, caregivers, health practitioners and a Community Research Advisory Committee in the File Hills Qu'Appelle Tribal Council. We sampled participants who were either coping with their own memory loss, caring for someone with dementia, or had knowledge of dementia programs and services. Interview data were gathered in three focus groups, two one-on-one interviews at a local Indigenous gathering place, and with one one-on-one telephone interview $(n=43)$. Many respondents recognized the value of technology for dementia care, but many responses reflected unmet needs related to technology infrastructure, with frequent mention of unstable internet access in and around Indigenous communities. Another, but related theme to lack of ICT infrastructure pertains to the general lack of computer use and low rates of exposure to ICT. Finally, data security concerns were evident with concerns voiced about ensuring safety and wellbeing of Indigenous older adults. We discuss these findings in the context of inaccessibility and argue for co-design of technology with Indigenous older adults with dementia.
\end{abstract}

Keywords: technology, Indigenous older adults, rural/remote communities, Indigenous healthcare, dementia care

\section{INTRODUCTION}

The rising rates of dementia among Indigenous peoples in Canada (see Figure 1 for a brief description) represent a growing concern, and because of these increases it is critical to provide culturally safe care and increase access to appropriate technology. Increased access to technology can promote independent living, stimulate cognitive functioning, relieve caregiver burden (Jodrell \& Astell, 2016), and be used to share cultural resources such as Indigenous language applications. Most assistive technology has been developed based on mainstream culture, but benefits have been demonstrated from the adop- tion of assistive technology by Indigenous peoples (e.g., Brusse, Gardner, McAullay, \& Dowden, 2014; Doessel, Travers \& Hunter, 2007; Eady, Herrington \& Jones, 2010; Hunter, Travers, \& McCulloch, 2003). Nevertheless, little research has related to technology development for Indigenous peoples (Jones, Jacklin, \& $\mathrm{O}^{\prime}$ Connell, 2017). Due to cultural, colonial, and other unique historical experiences, technology experiences of Indigenous peoples are complex (Maar et al. 2010), and it cannot be assumed the needs are equivalent to the needs and experiences of mainstream culture older adults. The aim of the current project is to understand the role of cultur- 


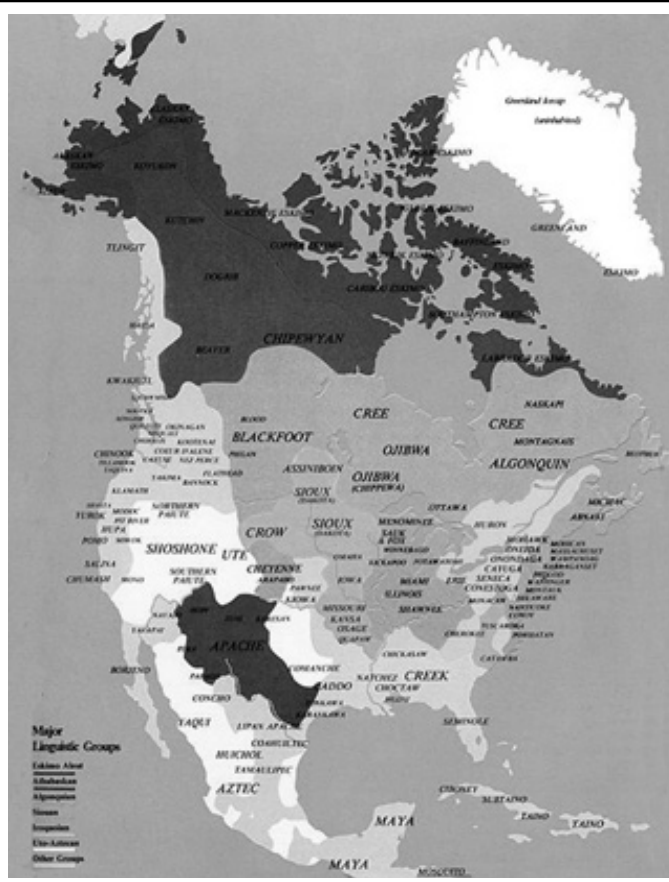

Figure 1. (Kairos Canada, 2015). The borders which currently separate North America did not exist in the times prior to European contact. The Indigenous people of North America, although diverse in language and culture, lived harmoniously with the land and travelled throughout the continent of North America, thus contributing to the current geographic distance leading to decreased access to technology (Yellowhorn \& Lowinger, 2017). The statistics of the Indigenous peoples of North America can be understood relative to each North American country. Indigenous people of Canada represent $4 \%$ of the total Canadian population (Statistics Canada, 2015). Indigenous people of the United States represent $1.7 \%$ of the total population (Norris, Vines \& Hoeffel, 2012) and finally, Indigenous people of Mexico represent 13\% of the total population (Minority Rights Group International, 2019).

ally appropriate technology in reducing healthcare disparities and improving dementia care for Indigenous older adults. Culturally appropriate technology might increase receptiveness and eagerness to adopt technology for use in dementia care. Considering the increasing rates and concern of dementia among Indigenous peoples, it is necessary to create and ensure equitable access to appropriate technologies.

Discovering technology needs is a critical component influencing an older person's willingness and ability to adopt new technology. Technology acceptance research suggests that when users are presented with a new technology a number of factors influence their decision about whether and how to use it, notably the perceived usefulness and perceived ease-of-use (Davies, Bukulatjpi, Sharma, Caldwell, Johnston, \& Davis, 2015;
Peek, Wouters, van Hoof, Luijkx, Boeije, \& Vrijhoef, 2014). Technology user needs differ for Indigenous peoples relative to the needs of older adults from mainstream society due to numerous historical and cultural factors (e.g., Jones, et al., 2017; Kirmayer, 2003; Maar, Seymour, Sanderson, \& Boesch, 2010). A recent systematic review by Jones and colleagues (2017) supported the need for technology collaborative research and development with Indigenous communities that recognize the importance of cultural values and community-based needs. Collaborative research and development of technologies not only ensures relevant and appropriate innovations, but also contributes to decolonization of the research process. Therefore, users of the technology, such as Indigenous older adults living with dementia, caregivers, healthcare professionals, and other community members, should be included in the development of new technologies. In addition, technology needs should be identified by the community involved in the collaboration. This ensures that new developments are appropriate for the community and addresses relevant needs of the community (Jones et al., 2017).

\section{Indigenous people of Canada and dementia}

Indigenous peoples, referring to the First Nations, Métis, and Inuit peoples of Canada, make up approximately $4 \%$ of the Canadian population (Statistics Canada, 2015), and rates of dementia amongst Indigenous older adults are reported to be $34 \%$ higher than the non-Indigenous population and rising quickly (Canadian Institutes of Health Research, 2017), but incidence and prevalence data are incomplete because there is a paucity of data for Métis and Inuit peoples (Petrasek MacDonald, Ward \& Halseth, 2018). There are multiple factors which may be contributing to the rise in dementia rates among Indigenous people, including an increased prevalence of persons aged 60 and older in the ensuring decades (Jacklin, Walker, \& Shawande, 2013). Although the proportion of older adults is increasing, Indigenous populations continue to have a shorter life expectancy: Métis and First Nations at 73.5 years for men and 79 years for women and Inuit at 64 years for men and 73 years for women, this is relative to the total Canadian population at 79 years for men and 83 years for women (Statistics Canada, 2016). First Nations peoples experience societal issues (i.e., social determinants of health) that reduce life expectancy and also increase risk of dementia, such as differential healthcare access, low income, few years of quality education, and higher rates of cardiovascular and metabolicrelated health conditions (Jacklin et al., 2013).

\section{Technology and access to healthcare}

A number of studies indicate that Indigenous seniors report a poorer health status than the 
general older population (Beatty \& Berdahl, 2011), due, at least in part, to the fact that many older Indigenous adults live in outlying regions of Canada. Geographic distance translates into less access to urban health services that can affect both quality and quantity of life (Keating, Swindle, \& Fletcher, 2011). Older adults living in rural/remote communities often lack the various social services (e.g., affordable housing, police, healthcare) that build stronger communities and promote opportunities to live a secure, healthy life. Lack of infrastructure creates reduced technology exposure to and comfort with technology, referred to as the second double digital divide (Crompton, 2004). Technology solutions are the ideal method to mitigate the health disparities seen in Indigenous communities (Jones et al., 2017; Mignone, \& Henley, 2009; Morrison, 2000). For example, remote presence technology allows for face-to-face communication through a "robot" with another person, and this has been used with Northern Indigenous communities (Allen, 2015; Mendez, Jong, KeysWhite, and Turner (2013).

\section{The Double Digital Divide}

The digital divide refers to the difference in access to internet, cell towers, and other ICT between individuals and communities. Indigenous communities in Canada can experience more inequities and lack of access to Internet and cell towers compared to non-Indigenous communities. Although the differences in access to ICT among Indigenous and non-Indigenous rural communities may be similar, for example, the quality of internet connection or speed of internet, some inequities exist for Indigenous populations who are also rural dwelling. For example, more Indigenous older adults, compared to non-Indigenous older adults, choose to age in place or age in their homes with the assistance of caregivers and family, and prefer this over moving to long-term care (Jones et al., 2017). Technology can act as a solution to maintain aging in place by promoting independent living and supporting caregivers of Indigenous older adults. Technology can also be used to share and teach Indigenous languages (Our Languages, 2014) for example, Indigenous language applications can teach older adults, or elicit early memories of, traditional languages which has benefit to brain structures sensitive to aging (Poisnel et al., 2018).

The digital divide can also refer to the lack of culturally appropriate technology or technology that reflects Indigenous culture (Jones et al., 2007). The first digital divide refers to the socioeconomic differences between people who utilize the internet and those who do not use the internet. For example, Indigenous and non-Indigenous internet users are more likely to have higher education, live in an urban area, be employed, and have a higher annual income compared to those who do not use the internet (Crompton, 2004). The second digital divide refers to the socioeconomic differences among those who use the internet. For example, most Indigenous internet users access the internet at home. However, rates of at-home use are lower among lowincome households. In addition, those who have employment use the internet at work and those with low-income or low educational attainment are more likely to use the internet in a school setting (Crompton, 2004). Thus, there are socioeconomic differences among internet users.

O'Connell and colleagues (2018) proposed a rural adaptation to the original technology acceptance model (TAM; Davis, 1989). The O'Connell et al. (2018) ruralTAM (Figure 2) underscores that the doubledigital divide experienced by rural and remote older adults impacts multiple levels important for perceived ease of use, perceived usefulness, and perceived access barriers to technology, which influence attitudes toward technology and usage of technology. In the 
ruralTAM lack of ICT access due to infrastructure creates lack of familiarity and ICT skill, which further decreases likelihood of adoption and sustained ICT use (O'Connell, et al., 2018). The digital divide in the context of healthcare refers to the potential for individuals without proper access or skills in using ICTs to become marginalized as traditional healthcare services become increasingly digitalized (Currie, Ronquillo, \& Dick, 2014).

\section{Technology and Indigenous communities}

While most Indigenous communities have some form of basic internet access, few (20\%) have the high-speed access to take full advantage of the internet (Kimery, \& Amirkhalkali, 2011). The lack of availability of services as well as unequal access to Canada's health system has been called one of the top five problems facing Indigenous people (Duenas, 2014). The situation is exacerbated by infrastructure challenges that make many systems outdated and unreliable (Canada's Public Policy Forum, 2014; Raven, Butler, \& Bywood, 2013). In First Nations and Inuit communities, Telehealth increases access to expert medical advice, links healthcare professionals, and encourages sharing of health information (Health Canada, 2003). Much of the barrier to technology for healthcare use might be cultural. A First Nations patient living in Northern Canada participating in a videoconference with an urban physician is likely to be connecting to someone who holds a biomedical perspective that leaves little room for traditional concepts of healing and health (Gibson, Coulson, Miles, Kakekekung, Daniels, \& O'Donnell, 2011). Additionally, there might be a language barrier for those Indigenous older adults whose first language is not English (O'Donnell, Beaton, McMahon, Hudson, Williams, \& Whiteduck, 2016). Miscommunication can have adverse consequences, including misdiagnosis, procedures being carried out without informed consent or poor adherence to treatment (Shahid, Finn, \& Thompson, 2009).

Perceived social class differences can also influence doctor-patient communications; for example, physicians have been found to deliver less information and supportive advice to minority patients who might be perceived to be of a lower socioeconomic class (Shahid et al., 2009). Some health professionals would prefer not to deal with attending family members (Shahid et al., 2009). For an Indigenous patient who values the involvement of extended family members, alienating one's family can be problematic. Research also suggests that Indigenous persons might be reluctant to access e-health services due to fear of judgmental and discriminatory attitudes (Awofesco, 2011; McCall \& Pauly, 2012). Thus, Indigenous patients may be deterred from accessing telehealth and ehealth services due to anticipated experiences of racism, language barriers, and lack of cultural safety among their healthcare providers. When a patient lives in a smaller community where everyone knows each other, they might be reluctant to approach an ehealth clinic and seek help because of a potential loss of anonymity and confidentiality (Shahid et al., 2009). Similar to small non-Indigenous communities, residence within a smaller Indigenous community can also pose challenges if that community is rural or remote. Although there are numerous benefits of technology use for both individuals living with dementia and their caregivers, technology developments must be created in collaboration with the users of the technology.

\section{Technology and dementia}

Technology use, such as Indigenous language applications, medication reminders, and cognitive health games, can have several benefits for people living with dementia and their caregivers. For example, technology can assist individuals to live independently, minimize anxiety and improve safety (Gibson, Dickinson, Brittain, \& Robinson, 2015). The development of Global Positioning Systems (GPS) for people living with dementia who wander is an example of improving safety (Mulvenna, Andrews \& Nugent, 2010). Technology can also decrease boredom while providing a stimulus to maintain cognitive abilities. As well, decreasing boredom may result in an increase in positive emotions. By promoting independence and autonomy, technology also decreases caregiver role strain and reliance on family caregivers for support (Jodrell \& Astell, 2016). Technology can also be used to test cognitive function for example, visual attention and working memory. In addition, there are many other benefits of technology such as stimulating conversation, assisting with activities of daily living, prompting memory, education, providing a method for reminiscence, and can be used in art and occupational therapy (Joddrell \& Astell, 2016).

This study aims to address this needed gap in the literature by exploring the views of technology held by Indigenous communities as they related to dementia care. Qualitative data was collected from caregivers of older adults requiring dementia care, healthcare providers and older adults living with dementia to provide further insight into improving access to supports and services needed to help them cope with the challenges of aging.

\section{Methods}

Forty-three individuals participated in the study through Research Focus Groups and individual One on One Interviews. Participants were recruited from two medical facilities serving Indigenous people located in Southern Saskatchewan, many of whom were members of First Nations 
belonging to the File Hills Qu'Appelle Tribal Council (FHQTC). Participants were recruited through existing community partnerships using Indigenous research methodologies such as community-based participatory research. A purposive sampling procedure was used in the selection of research participants based on one of the following: (1) Their firsthand knowledge of dementia programs and services;(2) Coping with their own memory loss; (3) Caring for someone with dementia. Due to the small sample size, identifying information must be limited. For this paper, the participants are described to the level they feel comfortable (i.e., due to a colonizing history that included residential schools as a method of cultural genocide, we would not ask demographic questions typically asked in research studies). Participant responses were gathered in three ways: (1) Three focus groups in which a total of forty participants were asked to share their feelings, experiences, and insights in response to specific, assigned topics; (2) Two one-on-one interviews at a local Indigenous gathering place where participants were asked a series of questions; and (3) One one-on-one telephone interview. Interview guides are included in Appendix V and Appendix VI.

Qualitative data $(n=43)$ was collected from caregivers of older adults requiring dementia care, healthcare providers, and older adults living with dementia to provide further insight into improving access to supports and services needed to help them cope with the challenges of aging. Respondents were asked about a range of issues, including gaps in healthcare, information needs, preventative measures and the emotional, physical, and social challenges faced by dementia patients and their caregivers. Using a combination of Indigenous research methods and community-based involvement, the research team refined the research process by working closely with healthcare providers, Indigenous advisors, older adults, and knowledge keepers.

\section{Community research}

This project aims to create more culturally safe care for Indigenous people with dementia in rural/remote areas, while simultaneously raising awareness and building capacity for increased technology use. A unique relationship with the File Hills Qu'Appelle Tribal Council (FHQTC) and the research team resulted in a collaborative partnership to undertake a dementia project to examine the issues facing Indigenous older adults requiring dementia care. The dementia project partners first signed the research agreement in 2015. The Research Team members worked together out of the All Nations Healing Hospital in Fort Qu'Appelle, SK and the Indigenous Community-Based Health Research Lab renamed the

Morning Star Lodge through ceremony, located in Regina, SK. They worked closely with the FHQTC Community Research Advisory Committee (CRAC). The CRAC guided them throughout their research processes. The CRAC is comprised of community representatives from each of the 11 First Nations belonging to the FHQTC: Carry the Kettle, Little Black Bear, Muscowpetung, Nekaneet, Okanese, Pasqua, Peepeekisis, Piapot, Standing Buffalo, Star Blanket, and Wood Mountain (Gail Boehme, Jessica Deiter, Elder Sylvia Obey, Elder Millie Hotomani, Lorna Breikreuz, Ethel DuBois, Lois Dixon, Lorraine Walker, Judy Sugar, Donna McKay, Richard Ironchild, Belinda Whitecap, Rozella McKay, Paulette, Gosselin, Natalie Jack, Cindy McArthur, Lorna Audette, Orval Spencer, Rhonda van der Breggen, Roxanne Quewezance, and Leona Peigan).

This study utilizes community research methodologies as the basis for the research. The work was driven by the community. A research agreement was signed between the Health Sciences North Research Institute (HSNRI) and the FHQTC Community Research Advisory Committee (CRAC) before any meetings or work began. The interview questions were initially drafted by the research team, and then the CRAC refined and re-drafted them. All interviews were audio recorded and transcribed by the research team. The Collective Consensual Data Analytic Procedure (CCDAP) adapted from a process developed by Métis physician and researcher Dr. Judith Bartlett (2006) was used to categorize and code the data into themes using NVivo as a first step. Ultimately however, the CRAC, the Community Research Assistant and the research team worked collaboratively to code the data into themes in a consensual manner. The CCDAP process is documented in Appendix I. This procedure ensured a high degree of consensus over the coding system and a high degree of consistency in its application.

All participants gave their consent prior to participating in the audio-recorded interviews and focus groups. The consent form also included information regarding retention of data and schedules for their disposal. The consent form informed participants that their participation was voluntary, and the information that they provided was confidential and would only be used for the purpose of the present study. Interview participants received a small honorarium. Elders and Knowledge Keepers were provided cloth and tobacco as per local cultural protocols.

The Rural/Remote Indigenous Technology Needs Exploration (RRITE) project uses Indigenous Research Methods and respects and prioritizes the Ownership, Control, Access, Possession (OCAP®) 
standards that establishes how First Nations data be collected, protected, used, and shared.

\section{Results \\ Research themes}

The interview questions were designed under the direction of CRAC and involved three broad categories: (1) Views about and experience with dementia and aging; (2) Healthcare practitioner experiences, and; (3) Access and experience with technology. The questions were developed in order to examine pathways to dementia care for Indigenous people.

Approximately 27 research themes were created by the CRAC during a series of meetings with the research team. Together they grouped the majority of the nodes and then named the groups to become the research themes. We identified 15 of the 27 research themes where responses were related to technology: Transition of Care, Interventions and Support, Memory Loss, Commitment to Loved One, Information Technology's, Access to Health Service and Care, Equipment Required for Care, Educational Information, Social Challenges, Effects of Dementia, Monitoring Mechanisms, Coping Memory Skills/Aids, Effect on Family/Caregiver, Miscellaneous, and Dementia Awareness.

\section{Research findings}

This study provided innovative ways for healthcare professionals and family members to discuss the technology needs and challenges of Indigenous older adults requiring dementia care, this was done under the guidance of the Community Research Advisory Committee (CRAC). The CRAC directed the process of naming the themes and subthemes and linking them to the appropriate underlying data from the focus group sessions and the interviews, this took place during a series of post interview meetings. The data was placed in the themes based on the discussions surrounding it. The data is presented below under the 15 technology relevant themes. Part of the CCDAP process includes co-design of how the results are presented. In this case, the CCDAP included explicit instructions to avoid imposition of higher order or inferential themes. In addition, a suggestion from the some of the researchers to re-organize the themes was rejected by the advisory group. They wanted their data to stand as they are - unblemished by others.

\section{Transition of care}

Transition of care includes how individuals respond to various activities. One respondent provided the following related to this theme:

- The use of games for patients with reading issues.

\section{Interventions and support}

This theme focused on improving quality of life:
- Ideas of technology to help dementia patients.

- That there are different types of technology to help dementia patients.

- Music affects memory.

- Reading is good.

- Using light as an aid (includes the sun).

- Use of audio technology and lifeline support technology.

- Talking on the phone is useful.

\section{Memory loss}

Family members and caregivers identified areas of concern related to safety:

- Issues around memory loss, such as taking care of banking issues, difficulty scheduling and remembering appointments, and regular use of medication.

\section{Commitment to loved one}

This theme was framed around how caregivers experience stress due to lack of services for their loved ones:

- Concerns regarding constant worrying about loved ones, to the point that the caregivers and/ or family members were losing sleep.

- Worrying about family members following medication schedules and supervision of them when they were in crowds.

\section{Information technologies}

A large number of respondents spoke about the access to the internet and lack of computer skills needed to stay up to date with technology:

- A lot of people do not have a computer, yet Skype was mentioned.

- Not knowing how to use a computer.

- Has internet at home.

- Does not have hi-speed internet.

- A family member used the internet to research their own health concern and the internet helped them with that.

- The limited information when they searched the internet.

- Have a TV, and a phone at home, some have cable.

- Caregivers have TV, phone and cable.

- The healthcare centre works with technology.

- Technology is worth it if it helps and technology would likely help to answer the questions about dementia.

- Effective use of technology with a doll that brings out the nurturing instinct.

- There is definitely room for technology if it is geared toward diagnosis.

- It would be beneficial for generations to come.

- Technology would aid in dementia care, but there is a hesitation due to privacy.

- Technology depends on community.

- Technology is inevitable. Times are changing.

- Although we use technology we also have to be careful with the internet, and take it with a 
grain of salt.

- Technology is scary, it can end up being a sin.

- Technology brings forward thoughts of computerized things.

- Supports anything that will help.

- Didn't know what technology is out there, but whatever is there that we could initiate would be a bonus.

- There are concerns about Lifeline technology and the costs associated with it.

- Technology takes away interaction and love there is no room for technology at an Elders age.

- Technology is useful for medicals but not for the dementia patient.

- Technology is a useful tool.

- Technology would help in dementia care.

- Tele-health benefits patients who cannot travel.

- Using technology for dementia is a good way to go.

- We need to understand dementia first before we bring in technology.

- There is a need for electronic records for immunizations.

- A pill app would have been good when their loved one was still alive.

- Wondering about medical alert for her dad, but it was not in this area, yet they needed something like that for their parents.

- No monitor, Iphone, or pager but their grandson has an Ipad.

- What is medical alert?

- No experience with monitor, pager, Iphone.

- People prefer a care aid or a healthcare provider by their side rather than having someone on the phone.

- We need to try harder to follow through with a teleconference.

- Google on the internet is a big thing, am able to find a lot.

- Experience with some technology.

- Everybody is scared of change, there exists an inexperience with computers.

- Due to location there is no access to the internet for caregiver or the person being cared for.

\section{Access to health service \& care}

The access to services and knowledge of how to integrate them into the care plan was evident in the responses:

- A telehealth conference will only work if there is follow through, but there is a need for it in rural areas.

- Telehealth is supposed to happen for mental health of person with Parkinson's and dementia, have been waiting for over a year.

- Used Telehealth and thinks it is great.

- A teleconference phone would take less time for appointments that are far away.

- Teleconference on a big screen computer would be beneficial for doctor consultations in rural areas.
- Was supposed to teleconference with the dementia doctor but there was a lack of organization on this.

\section{Equipment required for care}

Some respondents associated equipment with technology:

- Got help for wheelchair accessible equipment.

- Alternative technology might be machines that can calm people down.

- Technology is needed to ensure dementia patients are safe in their environment.

- Safety needs depend on the stage of dementia, lifts may be helpful depending on mobility, and alarms for doors in case they go outside.

- Is there was a tool to measure dementia diagnosis?

\section{Educational information}

Three respondents referred to the ways in which technology can help to educate them:

- Can dial two on one (sic) and they tell about the symptoms, it is a good referral service.

- Internet is not the gospel truth. We need to challenge what we believe for our benefit.

- Having a telephone is critical, some people can't afford it though, and access to a computer with internet is needed for research.

\section{Social challenges}

Family members stressed the challenges faced by their loved ones in meeting their social needs:

- It was hard to get mom to socialize, instead she plays crib with respite.

- Technology would help with socialization.

- Cell phone is very important for communication, this respondent texts a bit, but it is too expensive.

\section{Effects of dementia}

Two family members talked about the way dementia has changed their loved ones:

- The phone is good for person with dementia, because she doesn't remember who she is talking to.

- It is difficult to see strong mother like this, she reads a lot with repetition.

\section{Monitoring mechanisms}

Caregivers and healthcare professionals were increasingly concerned about safety, and the technology available to ensure safety:

- There was an instance where 2 patients left their care home at night, a GPS would help to watch them.

- Elderly mother uses Iphone, texts, and Facebook, she believes it is important to know the computer.

- Has alarm systems in their home.

- Technology is important for home alarms, getting in the bath is an area that would be beneficial. 
- A type of security alert is important for people with dementia, this respondent talked about mom wandering outside in her pyjamas.

\section{Coping memory skills/aids}

Some respondents commented on aids for improving memory, one respondent asked for more information:

- Can dementia be resolved by books and puzzles?

- Told to do puzzles and read but is not a good reader.

- Son is techy so he enlarged phone for her eyes, the phone is good and sometimes it's not.

\section{Effect on family/caregiver}

One respondent shared the mobility challenges her mother faced:

- Mom is in a wheelchair so it is hard to get around in the snow, they have had 7 incidents where she was almost toppled over.

\section{Miscellaneous}

The following were general responses related to technology use:

- Is not good with technology, prefers the house phone and the grandchildren's cells are always dead.

- Has not used Telehealth.

- Has internet and Wi-Fi because they live in the city.

- Has TV, cable, and cell phone.

- Has a Samsung android but didn't think mom could operate a touch phone.

- A large computer screen with video conferencing would be beneficial technology.

- Mom is a techno-peasant, but they personally like Facebook to keep in touch with family.

- They have no experience with monitors, pagers.

- Technology would help with socialization.

- Believes in having a telephone but is not into technology, yet admitted they should be.

- Likes music, DVD's, and the TV, loading medical books is important.

- Is not into technology, but if they learned how to utilize it right then it would be beneficial.

- Technology is important in today's age but it is hard for people to catch onto, and security is excellent for dementia.

- Technology can be good, TV, computers, music are all good if used in ways to help others.

- Technology and computers scare them, they accidentally erased everything on their daughters.

- Agrees with technology and Iphone, also Facebook to keep in touch, and for pictures, news, and information.

- The typewriter is not really good either.

\section{Dementia awareness}

Family members and caregivers identified ways to inform themselves about dementia:
- Watched a movie about dementia stages and they are praying and hoping they don't get to that stage, it is hard.

- The best way to learn is reading and research, sometimes doctors prescribe medication and they don't know what it's for.

- The most critical thing would be security for dementia because they don't understand that it's cold outside or really hot.

- Mom with dementia doesn't remember what she ate, so they have to monitor her for blood sugar.

- Can't sense danger outside when it is too hot or cold.

\section{Main findings}

The research data demonstrated the challenges facing Indigenous older adults requiring dementia care. Although most respondents demonstrated the lack of technology use overall, they were prepared to learn more about the potential uses of technology and technology related supports for dementia care. The main findings were as follows: - The respondents generally stated the internet is beneficial and that technology is inevitable.

- Many respondents recognized the value of technology.

- Respondents knew about Telehealth but none provided detail about its use.

- The lack of respondents' computer use was evident as was the unstable internet access in and around Indigenous communities.

- Also evident are problems around the technology infrastructure needs in Indigenous communities. There are a number of factors surrounding this.

- Personal security concerns were prominent in the data, ensuring safety and well-being of Indigenous older adults is something that makes their loved ones feel helpless. Suggestions were made for GPS or other tracking devices to be able to have a sense of security for family members.

\section{Discussion}

Respondents provided feedback around their experience with technology, specifically the internet and cellular phones. Although they were asked to consider various technologies that they would be comfortable with and the type of technology they thought caregivers would need, they responded using the language that was posed to them in the queries and spoke primarily about the internet, computers, and cellular phones. There was a consistent understanding from the respondents that use of technology would be beneficial. The limited responses to what types of technology would be valuable is attributed to the lack of detail provided to the respondents in defining technology in order to avoid leading responses.

These data are notable for two main reasons: First, community members expressed interest 
in exploring technology, and second, many reported barriers to technology use such as lack of reliable internet access. Although our data are limited by lack of information about participants prior exposure to technology, the responses from Indigenous community members appear similar in many ways to responses from the general rural and remote population: infrastructure challenges due to limited broad band internet access (Steele \& Lo, 2013). Similar to those residing in rural geographic locations, members of these Indigenous communities experience the 'digital divide' or experience less access to technology relative to urban dwellers. The digital divide also contributes to reduced exposure to technology (Haight, Quan-Haase, \& Corbett, 2014), which produces the second digital divide (e.g., Crompton, 2004) through lower comfort with, and exposure to, technology. This can be seen as similar to the 'double disparity' described for rural health providers (Harris, Beatty, Leider, Knudson, Anderson, \& Meit, 2016; Heisey-Grove, 2016) or to the 'double jeopardy' describing the social exclusion for rural adults (Park, 2017). Moreover, rural older adults face barriers to healthcare due to limited services and specialist access (Morgan et al., 2014; O'Connell, Crossley, Cammer, \& Morgan, 2014; Szymczynska, Innes, Mason, \& Stark, 2011). When referring to rural ICT, Salemink and colleagues (2017) described this as a rural paradox: those most in need have the least access to ICT. We can describe a similar process for Indigenous communities. Indigenous community members appear open to exploring technology for dementia care; and technology, such as Telehealth, which increases access to medical advice, links healthcare professionals, and encourages sharing of health information (Health Canada, 2003). Due to lack of access to services and poorer health status than the majority culture population (Beatty, \& Berdahl, 2011), Indigenous older adults would benefit greatly from technology facilitation of dementia care services, but they have the least access to such technology (Duenas, 2014; Kimery, \& Amirkhalkali, 2011). Indeed, given the nature of the lack of access and the degree of need, the rural paradox seen in Indigenous communities is arguably greater than for the majority culture rural population and should, instead, be termed the Indigenous ICT crisis.

Although these data are notable for their positive appraisal of technology, some concerns were raised about the appropriateness of technology for dementia care. Telehealth technologies have been successfully used in dementia care for cognitive assessments, patient management, and caregiver support (Azad, Amos, Milne, \& Power, 2012; Bowes, Dawson, \& McCabe, 2016; Kim, Jhoo, \& Jang, 2015; O'Connell et al, 2014).
Technology has been used to meet the needs of persons with dementia and their caregivers, for example, technology aids have been used to aid communication in persons with dementia (Alm, Astell, Ellis, Dye, Gowans, \& Campbell, 2004) and facilitate caregiver patient relationship (Astell et al., 2010). Changes in design interface can facilitate use by persons with dense amnesia (Alm, Dye, Astell, Ellis, Gowans, \& Campbell, 2005), such as is seen in dementia due to Alzheimer's Disease. Unfortunately, the majority of assistive technology has been developed through mainstream culture, without consideration of the characteristics of unique Indigenous groups. The lack of cultural appropriateness of technology could have contributed to the abovementioned concerns about technology for dementia care. Past research has supported the importance of cultural values and community-based needs, and thus some mainstream technology may not directly match the cultural needs for technology expressed by Indigenous communities (see review by Jones et al., 2017).

It could be argued, then, that Indigenous communities experience not only a double-digital divide or double-disparity, which have been described for rural residents, but rather experience a triple divide. Infrastructure challenges, exacerbating comfort with and exposure to technology, and lack of culturally safe technologies providing yet another barrier. Indigenous communities are open to technology, express numerous needs for dementia care that could be addressed with technology, but access barriers caused by infrastructure and cultural appropriateness need to be addressed. Technology that is developed with, rather than for Indigenous communities is more likely to experience sustained adaptation (Jones et al., 2017) and has the potential to make the largest impact in terms of reducing health disparities and improve dementia care. These data are important for emphasizing that the Indigenous peoples in this study were open to use of technology for monitoring to promote safety of persons living with dementia. Development of monitoring technology in particular will require co-design to mitigate concerns about privacy to maintain cultural safety.

\section{Conclusion}

The present study sets the stage to further explore the utility of technological services in dementia care for Indigenous communities by identifying their general reactions and thoughts towards technology and dementia care, and the various barriers that impact effective technological development (e.g., access to services; connectivity issues; unique culture). Indigenous older adults requiring dementia care and residing in rural and remote areas require specific technology in order 
to improve their quality of life and in order to age in place. Accessibility and readiness are key areas that require attention and strategic approaches in order to improve the current situation.

\section{Acknowledgements}

All This work was supported by AGE-WELL NCE Inc., a member of the Networks of Centres of Excellence program.

\section{References}

Alexander, C. J. (2001). Wiring the nation! Including First Nations? Aboriginal Canadians and federal egovernment initiatives. Journal of Canadian Studies, 35(4), 277-296.

Allen, B. (2015, February 23). 5 ways robots are delivering health care in Saskatchewan. CBC News. Retrieved from http://www.cbc.ca/news/canada/ saskatchewan/5-ways-robots-are-deliveringhealth-care-in-saskatchewan-1.2966190

Alm, N., Astell, A., Ellis, M., Dye, R., Gowans, G., \& Campbell, J. (2004). A cognitive prosthesis and communication support for people with dementia. Neuropsychological Rehabilitation, 14(1-2), 117-134.

Alm, N., Dye, R., Astell, A., Ellis, M., Gowans, G., \& Campbell, J. (2005). A computer-based hypermedia conversation support for people with dementia. Paper presented at the Proceedings of the CSUN Conference on Technology and Disability, Los Angeles, CA.

Astell, A. J., Ellis, M. P., Bernardi, L., Alm, N., Dye, R., Gowans, G., \& Campbell, J. (2010). Using a touch screen computer to support relationships between people with dementia and caregivers. Interacting with Computers, 22(4), 267-275.

Awofeso, N. (2011). Racism: A major impediment to optimal Indigenous health and health care in Australia. Australian Indigenous Health Bulletin, 11(3), 1-8.

Azad, N., Amos, S., Milne, K., \& Power, B. (2012). Telemedicine in a rural memory disorder clinic-Remote management of patients with dementia. Canadian Geriatrics Journal, 15(4), 96-100. http://doi. org/10.5770/cgj.15.28

Bartlett, J. (2006). Collective Consensual Data Analytic Procedure (CCDAP).

Beatty, B. B., \& Berdahl, L. (2011). Health care and Aboriginal seniors in urban Canada: Helping a neglected class. The International Indigenous Policy Journal, 2(1), 10.

Bowes, A., Dawson, A., \& McCabe, L. (2016). RemoDem: Delivering support for people with dementia in remote areas. Dementia. Retrieved from http://journals.sagepub.com/doi/ abs/10.1177/1471301216643848

Brusse, C., Gardner, K., McAullay, D., \& Dowden, M. (2014). Social media and mobile apps for health promotion in Australian Indigenous populations: Scoping review. Journal of Medical Internet Research, 16(12).

Canada's Public Policy Forum. (2014). Northern connections: Broadband and Canada's digital divide. Retrieved from https://issuu.com/ppforumca/docs/ broadband_final

Canadian Institutes of Health Research. (2017). Government of Canada invests in dementia research about Indigenous Peoples. Retrieved from https:// www.canada.ca/en/institutes-health-research/ news/2017/02/government_of_canadainvestsindementiaresearchaboutindigenouspeop.html

Caron-Malenfant, É., \& Morency, J.-D. (2011). Population projections by Aboriginal Identity in Canada, 2006 to 2031. Retrieved from http://www.statcan. gc.ca/pub/91-552-x/91-552-x2015001-eng.htm

Crompton, S. (2004). Off-reserve Aboriginal internet users. Canadian Social Trends, 8, 10-17. Retrieved from http://www5.statcan.gc.ca/olc-cel/olc. action?objld=11-008-X20040037732\&objType $=47$ \&lang $=$ en\&limit $=0$

Currie, L. M., Ronquillo, C., \& Dick, T. (2014). Access to internet in rural and remote Canada. Studies in Health Technology and Informatics, 407-412. Retrieved from http://ebooks.iospress.nl/publication/36622. https://doi.org/10.3233/978-1-61499415-2-407

Davies, J., Bukulatjpi, S., Sharma, S., Caldwell, L., Johnston, V., \& Davis, J. S. (2015). Development of a culturally appropriate bilingual electronic app about Hepatitis B for Indigenous Australians: Towards shared understandings. JMIR Research Protocols, 4(2), e70. https://doi.org/10.2196/resprot.4216

Davis, F. D. (1989). Perceived usefulness, perceived ease of use, and user acceptance of information technology. MIS Quarterly, 319-340.

Doessel, D., Travers, H., \& Hunter, E. (2007). The use of touch-screen technology for health-related information in Indigenous communities: Some economic issues. Prometheus, 25(4), 373-392.

Duenas, E. (2014). 5 problems facing the Indigenous people of Canada. Retrieved from https://www. care2.com/causes/5-problems-facing-the-aboriginal-people-of-canada.html

Eady, M., Herrington, A., \& Jones, C. (2010). Literacy practitioners' perspectives on adult learning needs and technology approaches in Indigenous communities. Australian Journal of Adult Learning, 50(2), 260.

Gibson, K. L., Coulson, H., Miles, R., Kakekakekung, C., Daniels, E., \& O'Donnell, S. (2011). Conversations on telemental health: Listening to remote and rural First Nations communities. Rural Remote Health, 11(2), 1656.

Gibson, G., Dickinson, C., Brittain, K., \& Robinson, L. (2015). The everyday use of assistive technology by people with dementia and their family carers: A qualitative study. BMC Geriatrics, 15. https://doi. org/10.1186/s12877-015-0091-3

Greenway-Crombie, A., Snow, P., Disler, P., Davis, S., \& Pond, D. (2012). Influence of rurality on diagnosing dementia in Australian general practice. Australian Journal of Primary Health, 18(3), 178-184. https:// doi.org/10.1071/PY12008

Haight, M., Quan-Haase, A., \& Corbett, B. A. (2014). Revisiting the digital divide in Canada: The impact of demographic factors on access to the internet, level of online activity, and social networking site usage. Information, Communication \& Soci- 
ety, 17(4), 503-519. https://doi.org/10.1080/136911 8X.2014.891633

Harris, J. K., Beatty, K., Leider, J., Knudson, A., Anderson, B. L., \& Meit, M. (2016). The double disparity facing rural local health departments. Annual Review of Public Health, 37, 167-184. https://doi. org/10.1146/annurev-publhealth-031914-122755

Health Canada. (2003). Closing the gaps in Aboriginal health. Health Policy Research Bulletin, (5). Retrieved from http://publications.gc.ca/collections/ Collection/H12-36-05-2003E.pdf

Heisey-Grove, D. M. (2016). Variation in rural health information technology adoption and use. Health Affairs, 35(2), 365-370. https://doi.org/10.1377/ hlthaff.2015.0861

Hunter, E., Travers, H., \& McCulloch, B. (2003). Bridging the information gap: IT and health in Indigenous populations. Australasian Psychiatry, 11(sup1), S51-S56.

Innes, A., Szymczynska, P., \& Stark, C. (2014). Dementia diagnosis and post-diagnostic support in Scottish rural communities: Experiences of people with dementia and their families. Dementia, 13(2), 233247. https://doi.org/10.1177/1471301212460608

Jacklin, K. M., Walker, J. D., \& Shawande, M. (2013). The emergence of dementia as a health concern among First Nations populations in Alberta, Canada. Canadian Journal of Public Health, 104(1), e39-e44.

Joddrell, P., \& Astell, A. J. (2016). Studies involving people with dementia and touchscreen technology: A literature review. JMR Rehabilitation and Assistive Technologies, 3(2). https://doi.org/10.2196/rehab.5788

Jones, L., Jacklin, K., \& O'Connell, M. E. (2017). Development and use of health-related technologies in indigenous communities: Critical review. Journal of Medical Internet Research, 19(7), e256. http://doi. org/10.2196/jmir.7520

Kairos Canada. (2015). Territorial acknowledgement as an act of reconciliation. Retrieved from https://www. kairoscanada.org/territorial-acknowledgment

Keating, N., Swindle, J., \& Fletcher, S. (2011). Aging in rural Canada: A retrospective and review. Canadian Journal on Aging, 30(3), 323-338.

Kim, H., Jhoo, J. H., \& Jang, J.-W. (2017). The effect of telemedicine on cognitive decline in patients with dementia. Journal of Telemedicine and Telecare, 23(1), 149-154. https://doi. org/10.1177/1357633X15615049

Kimery, K. M., \& Amirkhalkhali, S. (2011). Information and communication technologies and Aboriginal peoples in Canada: Information seeking, community building, and access challenges in geographically and socially marginalized populations. International Journal of Management and Information Systems, 15(4), 41-45.

Kirmayer, L., Simpson, C., \& Cargo, M. (2003). Healing traditions: Culture, community and mental health promotion with Canadian Aboriginal peoples. Australasian Psychiatry, 11(sup1), S15-S23.

Kosteniuk, J., Morgan, D., Innes, A., Keady, J., Stewart, N., D'Arcy, C., \& Kirk, A. (2014). Who steers the ship? Rural family physicians' views on collaborative care models for patients with dementia. Primary Health care Research \& Development, 15(1), 104-
110. https://doi.org/10.1017/S146342361300011X

Maar, M., Seymour, A., Sanderson, B., \& Boesch, L. (2010). Reaching agreement for an Aboriginal ehealth research agenda: The Aboriginal telehealth knowledge circle consensus method. Rural Remote Health, 10(1), 1299. Retrieved from https:// www.rrh.org.au/journal/article/1299

McBain, L., \& Morgan, D. (2005). Telehealth, geography and jurisdiction: Issues of health care delivery in northern Saskatchewan. Canadian Woman Studies, 24(4), 123-129.

McCall, J., \& Pauly, B. (2012). Providing a safe place: Adopting a cultural safety perspective in the care of Aboriginal women living with HIV/AIDS. CJNR (Canadian Journal of Nursing Research), 44(2), 130-145.

Mendez, I. (2016). Remote presence technology: The Saskatchewan experience. Canadian Healthcare Technology. Retrieved from http://www.canhealth. com/blog/remote-presence-healthcare-technology-the-saskatchewan-experience/

Mendez, I., Jong, M., Keays-White, D., \& Turner, G. (2013). The use of remote presence for health care delivery in a northern Inuit community: A feasibility study. International Journal of Circumpolar Health, 72(1), 21112. https://doi.org/10.3402/ijch. v72i0.21112

Mignone, J., \& Henley, H. (2009). Implementation of information and communication technology in Aboriginal communities: A social capital perspective. The Journal of Community Informatics, 5(2). Retrieved from http://ci-journal.net/index.php/ciej/ article/view/511/446

Minority Rights Group International. (2019). Mexico Indigenous peoples. World Directory of Minorities and Indigenous Peoples. Retrieved from https://minorityrights.org/minorities/indigenous-peoples-4/

Morgan, D. G., Walls-Ingram, S., Cammer, A., O'Connell, M. E., Crossley, M., Dal Bello-Haas, V., Forbes, D., Innes, A., Kirk, A., \& Stewart, N. (2014). Informal caregivers' hopes and expectations of a referral to a memory clinic. Social Science \& Medicine, 102, 111-118. https://doi.org/10.1016/j.socscimed.2013.11.023

Morrison, P. (2000). A pilot implementation of Internet access for remote Aboriginal communities in the 'Top End' of Australia. Urban Studies, 37(10), 1781-1792.

Mulvenna, M. D., Andrews, J., \& Nugent, C. D. (2010). Supporting people with dementia using pervasive health technologies. https://doi.org/10.1007/978-184882-551-2

Muttitt, S., Vigneault, R., \& Loewen, L. (2004). Integrating telehealth into Aboriginal healthcare: The Canadian experience. International Journal of Circumpolar Health, 63(4), 401-414.

Norris, T., Vines, P. L., \& Hoeffel, E. M. (2012). The American Indian and Alaska Native population: 2010. 2010 Census Briefs. Retrieved from https:// www.census.gov/history/pdf/c2010br-10.pdf

O'Connell, M. E., Crossley, M., Cammer, A., Morgan, D., Allingham, W., Cheavins, B., Dalziel, D., Lemire, M., Mitchell, S., \& Morgan, E. (2014). Development and evaluation of a telehealth videoconferenced support group for rural spouses of individuals diagnosed with atypical early-onset 
dementias. Dementia, 13(3), 382-395. https://doi. org/10.1177/1471301212474143

O'Connell, M. E., Wiley, K., Gould, B., Scerbe, A., Carter, J., Bourassa, C., Morgan, D., Jacklin, K., \& Warry, W. (2018). Anticipated needs and worries about maintaining independence of rural/remote older adults: Opportunities for technology development in the context of the double digital divide. Gerontechnology.

O'Donnell, S., Beaton, B., McMahon, R., Hudson, H. E., Williams, D., Whiteduck, T., \& First Nations Education Council. (2016). Digital technology adoption in remote and northern Indigenous communities in Canada. Paper presented at the Canadian Sociological Association 2016 Annual Conference. University of Calgary, Calgary, Alberta.

Our Languages. (2014). Tradition meets technology with Indigenous language app. International. Retrieved from http://ourlanguages.org.au/tradition-meetstechnology-with-indigenous-language-app/

Pace, J. E. (2013). Meanings of memory: Understanding aging and dementia in First Nations communities on Manitoulin Island, Ontario. (PhD), McMaster University, Hamilton, ON. Retrieved from https:// macsphere.mcmaster.ca/bitstream/11375/13464/1/ fulltext.pdf

Park, S. (2017). Digital inequalities in rural Australia: A double jeopardy of remoteness and social exclusion. Journal of Rural Studies, 54, 399-407. https:// doi.org/10.1016/j.jrurstud.2015.12.018

Peek, S. T., Wouters, E. J., van Hoof, J., Luijkx, K. G., Boeije, H. R., \& Vrijhoef, H. J. (2014). Factors influencing acceptance of technology for aging in place: A systematic review. International Journal of Medical Informatics, 83(4), 235-248.

Petrasek MacDonald, J., Ward, V., \& Halseth, R. (2018). Alzheimer's disease and related Dementias in Indigenous populations in Canada: Prevalence and risk factors. National Collaborating Centre for Aboriginal Health. Retrieved from https://www.ccnsanccah.ca/docs/emerging/RPT-Alzheimer-Dementia-MacDonald-Ward-Halseth-EN.pdf

Poisnel, G., Arenaza-Urquijo, E., Collette, F., Klimecki, O. M., Marchant, N. L., Wirth, M., de La Sayette, V., Rauchs, G., Salmon, E., Vuilleumier, P., Frison, E., Maillard, A., Vivien, D., Lutz, A., Chételat, G., \& the Medit-Ageing Research Group. (2018). The Age-Well randomized controlled trial of the Medit-Ageing European project: Effect of meditation or foreign language training on brain and mental health in older adults. Alzheimer's \& Dementia: Translational Research \& Clinical Interventions, 4, 714-723. https://doi.org/10.1016/j. trci.2018.10.011

Raven, M., Butler, C., \& Bywood, P. (2013). Videobased telehealth in Australian primary health care:
Current use and future potential. Australian Journal of Primary Health, 19(4), 283-286.

Reading, C. L., \& Wien, F. (2009). Health inequalities and the social determinants of Aboriginal peoples' health. Prince George, BC: National Collaborating Centre for Aboriginal Health. Retrieved from https://www.ccnsa-nccah.ca/docs/determinants/RPTHealthlnequalities-Reading-Wien-EN.pdf.

Romanow, R. J. (2002). Building on values: The future of health care in Canada. Ottawa, ON: Government of Canada. Retrieved from http://publications. gc.ca/collections/Collection/CP32-85-2002E.pdf.

Salemink, K., Strijker, D., \& Bosworth, G. (2017). Rural development in the digital age: A systematic literature review on unequal ICT availability, adoption, and use in rural areas. Journal of Rural Studies, 54, 360-371. https://doi.org/10.1016/j. jrurstud.2015.09.001

Shahid, S., Finn, L. D., \& Thompson, S. C. (2009). Barriers to participation of Aboriginal people in cancer care: Communication in the hospital setting. Medical Journal of Australia, 190(10), 574-579.

Statistics Canada. (2015). Aboriginal Peoples: Fact Sheet for Canada. Retrieved from https://www150. statcan.gc.ca/n1/pub/89-656-x/89-656-x2015001eng.htm

Statistics Canada. (2016). Canadian Demographics at a Glance. Retrieved from http://www.statcan.gc.ca/ pub/91-003-x/2007001/4129904-eng.htm

Steele, R., \& Lo, A. (2013). Telehealth and ubiquitous computing for bandwidth-constrained rural and remote areas. Personal and Ubiquitous Computing, 17(3), 533543. https://doi.org/10.1007/s00779-012-0506-5

Szymczynska, P., Innes, A., Mason, A., \& Stark, C. (2011). A review of diagnostic process and postdiagnostic support for people with dementia in rural areas. Journal of Primary Care \& Community Health, 2(4), 262-276. https://doi. org/10.1177/2150131911404705

Topo, P. (2008). Technology studies to meet the needs of people with dementia and their caregivers. Journal of Applied Gerontology, 28(1), 5-37. https://doi. org/10.1177/0733464808324019

Wilson, K., \& Cardwell, N. (2012). Urban Aboriginal health: Examining inequalities between Aboriginal and non-Aboriginal populations in Canada. The Canadian Geographer/Le Géographe Canadien, 56(1), 98-116.

Yellowhorn, E., \& Lowinger, K. (2017). Turtle Island: The story of North America's first people. Ontario: Annick Press Ltd.

Young, T. K., Ng, C., \& Chatwood, S. (2015). Assessing health care in Canada's North: What can we learn from national and regional surveys? International Journal of Circumpolar Health, 74(1), 28436.

\section{Appendix I - Collective Consensual Data Ana- lytic Procedure (CCDAP)}

The following outlines the CCDAP process:

1. Create a PowerPoint presentation with theme names in the title box and a summary description in the body of a single slide.
2. Create a blank table with symbols at the top of each column. Symbols are used to avoid prenaming the themes.

3. Gather a group of people involved with the research (in this case, the Community Research Advisory Committee and research team). 
4. Two facilitators take turns reading out the titles and descriptions.

5. The first sub-theme's name and description is read out and then it is placed on the "wall" under the first symbol column.

6 . The next sub-theme name and description is read out and the group decides if it is the same (similar) or different than the first theme name that was placed.

a. If it is the theme is the same, it is placed under the first symbol; if the theme is different, it is placed under a new symbol.

7. This process is repeated, placing themes under existing symbols or new empty symbols in columns until all of the themes are placed.

a. If there is difficulty placing a theme it is put to the side and will be read out again when all the other sub-themes are placed.

8 . Once all the sub-themes are placed and the columns are established, the facilitators read out the sub-theme names contained in the first column, reading the summary description if necessary.

a. The group collectively decides if all of the cards underneath that symbol still belong there or should be moved; once that column has been finalized the group gives it a name that describes the content.

9. This process is repeated with all the columns until they are all named and the major themes are established.

10. Reflection on the process and the themes is undertaken.

a. Each member of the group is encouraged to think about what is contained within a single column/theme and to share any analytical thoughts with the group; reflection is typically recorded and notes are taken.

b. This informationis used to help guide the writing process.

11. The theme areas are then entered into $\mathrm{NVi}$ vo (and potentially in an Excel spreadsheet for greater accessibility), grouped according to the collective process, and linked to the appropriate underlying data.

\section{Appendix II - Community Research Advisory Committee (CRAC)}

Lorna Audette - Health Director; Carry the Kettle

First Nation

Gail Boehme - Executive Director, All Nations

Healing Hospital/File Hills Qu'Appelle Tribal

Council Health Services

Lorna Breikreuz - Director, Client Services

Jessica Dieter - Community Research Assistant;

Okanese First Nation

Lois Dixon - Community Health Nurse, File Hills

Health

Ethel Dubois - Mental Health Therapist; Star

Blanket Cree Nation

Paulette Gosselin - former Health Director; Muscowpetung First Nation
Mildred Hotomani - Carry the Kettle First Nation Richard Ironchild - Piapot First Nation

Natalie Jack - Carry the Kettle First Nation

Cindy McArthur - Health Director; Standing Buf-

falo First Nation

Donna McKay - Community Health Representa-

tive; Peepeekisis First Nation

Rozella McKay - Standing Buffalo First Nation

Sylvia Obey - Piapot First Nation

Leona Peigan - Health Staff; Pasqua First Nation

Roxanne Quewezance - Manager, Lakeview

Lodge Personal Care Home; Muscowpetung First

Nation

Orval Spencer - Carry the Kettle First Nation

Judy Sugar - Health Director; Piapot First Nation

Rhonda van der Breggen - Health Staff; Pasqua

First Nation

Lorraine Walker - Health Director of File Hills Health; Okanese First Nation

\section{Appendix III - Focus group questions}

Views About and Experience with Dementia/Aging 1. How do you think your memory is, and/or the person who you are caring for \& what have you witnessed or experienced that made you think you have, or a person you are caring for, has dementia?

Health Care Practitioner Experiences

2. How comfortable are you seeing a health care practitioner \& are there problems with seeing a health care practitioner?

Access and Experience with Technology

3. What kind of technology would you be comfortable with \& what type of technology do you think your caregivers would need, to help take care of you?

\section{Appendix IV - Key informant interview ques- tions - Healthcare professional}

Health Care Professional

REB INFO: (1) We anticipate conducting 10 key informant interviews with health care professionals and traditional healers/coordinators to examine pathways to dementia care for Indigenous people.

1. Do you feel like you know enough about services available to help those who have a type of dementia? (do you think you have enough education or information to help those who have a type of dementia)

2. What is your training and education regarding dementia?

3. In your work, have you come across many people who have dementia or display any signs of dementia?

4. Where would you direct patients or caregivers who are concerned about their loved ones having dementia? (facilities, referrals, specialists that are dementia specific) 
5. Have people contacted you with concerns about their loved ones having dementia?

6 . On a scale from $1-5$, with 1 being very uncomfortable and 5 being very comfortable, how do you feel about providing care for people living with dementia?

7. On scale from $1-5$, with 1 being very uncomfortable and 5 being very comfortable, how do you feel addressing the needs of those who live with dementia?

8. Do you believe there is benefit in bringing Indigenous knowledge into dementia care services for clients? (ceremony, prayer, smudging, use of traditional medicine)

9. Do your clients/patients have experience with technology (TV, cable, phone, computer, pager) and which of these forms of technology do they have access to in their home?

10. What kind of technology would your clients/ patients be comfortable with \& what type of technology do you think their caregivers would need, to help take care of them?

11. Is there anything you would like to add about your experiences?

\section{Appendix V - Key informant interview ques- tions - Elders/knowledge keepers/healers \\ Elders/Knowledge Keepers/Healers}

REB INFO: (2) We will interview 5 traditional knowledge keepers, Elders and healers to examine cultural strengths and mechanisms related to cognitive health

1. What do you know about dementia?

2. Are there any traditional teachings that you

have learned about aging and memory?

3. Are there traditional ways or practices you can recommend to strengthen memory? (songs, games, oral memory, storytelling, ceremony)

4. Do you believe that your language (mother tongue) would be beneficial for helping memory? 5. Do you think there is a connection to the use of language and memory? If so, can you speak to that? 6. Do you know of anything that can help improve memory? (medicinal plants, teas, etc.)

7. Do people in your community have experience with technology (TV, cable, phone, computer, pager) and which of these forms of technology do they usually have access to in your home?
8. What kind of technology would people in your community be comfortable with \& what type of technology do you think their caregivers would need, to help take care of them?

9. Is there anything you would like to add about your experiences?

\section{Appendix VI - Key informant interview ques- tions - Program coordinators/managers/direc- tors at the local/regional/national levels}

Program coordinators/managers/directors at the local/regional/national levels

REB INFO: (3) We will interview program coordinators/managers/directors at the local, regional and national levels to determine the feasibility of integration of cultural activities into existing models of care. We will not know the number of interviews necessary in the category until we have fully assessed program availability in the region.

1. Do you believe there is a need for including Indigenous knowledge into your programming for dementia care?

2. What kind of partnerships or outreach programs have you done with Indigenous communities and/or organizations?

3. Are there funds available to implement Indigenous cultural programming into existing models of care specific to Dementia?

4. Do your programs/funding reflect the needs of your communities?

5. What steps need to be taken in order to implement Indigenous knowledge into your current programming specific to Dementia?

6. How are you prioritizing Indigenous health in regards to the aging population?

7. What would you do to address the lack of resources available? (Elders, staff, information, location, Indigenous community connection)

8. Do your clients/patients have experience with technology (TV, cable, phone, computer, pager) and which of these forms of technology do they usually have access to in their home?

9. What kind of technology would your clients/ patients be comfortable with \& what type of technology do you think their caregivers would need, to help take care of them?

10. Is there anything you would like to add about your experiences? 